\title{
Comparing the adverse outcomes of contraception failure between IUD and withdrawal methods
}

\author{
Zahra Majdfar ${ }^{1}$, Maryam Meshkat $^{2}$, Anahita Tavana ${ }^{3}$, Shahrzad Tavana $^{3}$, \\ Zohreh Amiri ${ }^{4}$, Farnaz Ehdaeevand ${ }^{1}$, Nasrin Saharkhiz ${ }^{2}$, Masoumeh Fallahian ${ }^{2} *$
}

\author{
${ }^{1}$ Office of Reproductive Health, Vice-chancellor for Health Affairs, Shahid Beheshti University of Medical Sciences, \\ Tehran, Iran \\ ${ }^{2}$ Infertility and Reproductive Health Research Centre, Taleghani Hospital, Shahid Beheshti University of Medical \\ Sciences, Tehran, Iran \\ ${ }^{3}$ Department of Natural Sciences, University of Texas, Austin, TX, USA \\ ${ }^{4}$ National Nutrition and Food Technology Research Institute, Faculty of Nutrition Sciences and Food Technology, \\ Shahid Beheshti University of Medical Sciences, Tehran, Iran
}

Received: 6 July 2014

Accepted: 13 July 2014

\section{*Correspondence:}

Dr. Masoumeh Fallahian,

E-mail: m_fallahian@yahoo.com

(C) 2014 Majdfar Z et al. This is an open-access article distributed under the terms of the Creative Commons Attribution Non-Commercial License, which permits unrestricted non-commercial use, distribution, and reproduction in any medium, provided the original work is properly cited.

\begin{abstract}
Background: Objective of current study was to compare the adverse outcomes of pregnancy after failure of IUD (Intrauterine device) with the withdrawal method of contraception in order to predict and prevent such outcomes.

Methods: In a retrospective cohort study, the adverse outcomes of 224 pregnancies (2 groups, 112 women each) were assessed following failure of the IUD or withdrawal methods of contraception (coitus interruptus). Data were analyzed and $\mathrm{P}$ values $\leq 0.05$ were considered statistically significant.

Results: Rates of spontaneous and induced abortion, ectopic pregnancy, and vaginal bleeding during second half of pregnancy were more common in the removed IUD group compared to the withdrawal method, differences however not significant. No fetal abnormality was observed in IUD group. Preterm birth $(\mathrm{p}=0.045)$, preterm premature rupture of membrane $(\mathrm{p}=0.01)$, and vaginal bleeding during pregnancy $(\mathrm{p}=0.01)$, were more prevalent in the IUD group (retained and removed) compared to those using the withdrawal method.

Conclusions: Considering the adverse outcomes, we knew women with pregnancy after failure of IUD were at an increased risk for such outcomes, compared to those using the withdrawal method; however the results of this research showed these adverse effects are not significant when pregnancy with IUD is detected earlier and IUD is removed during the early stage(s) of pregnancy.
\end{abstract}

Keywords: IUD, Coitus interruptus, Contraception, Pregnancy

\section{INTRODUCTION}

IUD is one of the effective methods of contraception. According to the 2011 Iranian Demographic Health Survey (DHS), 21493000 married women, age range 1549 years, were eligible for contraception in Iran; among them, 60 percent used an effective modern contraception method and 21.66 percent used traditional methods. Compared to the IUD, a modern method of contraception used by $8 \%$ (1.7 million) of women, withdrawal, a traditional and less effective method, is the most common method of contraception used by $21 \%$ of clients in Iran. ${ }^{1}$

The withdrawal method has a high failure rate and leads to around $50 \%$ of unsafe abortions. ${ }^{2}$ On the other hand, although IUD is an effective contraceptive method, pregnancy due to failure of this method has its adverse effects; the failure rate of $\mathrm{Cu}-\mathrm{IUD}$ s is $0.8 \%(0.1-1.4$ per $100)^{3,4}$ and in Iran, pregnancy with this method is 
continued unless the mother is at risk. The IUD is removed in case of visibility of its tail. Spontaneous abortion and preterm labour are more frequent in pregnancies with IUD, whether it is retained or removed. ${ }^{5}$

Considering the high prevalence of IUD as a contraceptive method in Iran, we conducted this study in order to assess the adverse outcomes of pregnancy due to failure of this method among a group of $\mathrm{Cu}$ 380A IUD users, compared to a control group, comprising women who conceived due to a failure of withdrawal method (coitus interruptus).

\section{METHODS}

A retrospective cohort study was conducted from March 2011 to March 2013. The section of reproductive health affiliated with the office of the vice - chancellor for health affairs in Shahid Beheshti University of medical sciences covers and supervises family planning services for 215,775 married women in the age range of 15-49 years. Of this population, $16.7 \%$ (36034 clients) use IUD as a contraception method. ${ }^{6}$ Criteria for insertion of IUD, type of IUD (Cu380A), and the policy for the follow up of clients were the same in all public clinics. Clients receive full counseling about the advantages and disadvantages of the methods of contraception. Pregnancy termination after the failure of contraception is not allowed in health centres unless the mother is at serious risk, or foetal major abnormality has been confirmed before 18 weeks of pregnancy; however, post abortion care is available for women who have any complications due to abortion.

In this study, records of 224 clients, who had failure of IUD or withdrawal contraception, were collected. Categorized into two groups $(n=112$ each), the sample size of 220 participants were calculated: Significance level $(\alpha=5 \%)$, power $=80 \%$, ratio of sample size $(\mathrm{B}: \mathrm{A})=$ 1 , odds ratio of $\mathrm{A}$ to $\mathrm{B}=3$, approximately $95 \%$ confidence interval observed difference \pm 0.106 . Criteria for inclusion were records of the women participants, who had been visited, been offered counseling for contraception, had continued their pregnancies after contraceptive failure, and had received prenatal care and been delivered at the said public health centers. Incomplete records of clients were excluded if follow up of pregnancy and delivery child birth had not been done at these public health centers.

Demographic and socio-economic parameters were similar between the clients. Other variables were pregnancy and parity score, continuation of the method and reproductive indicators. In order to assess the adverse outcomes of pregnancy after failure of IUD, we compared the rate of ectopic pregnancy, abortion, vaginal bleeding, preterm labour and preterm premature rupture of membrane, late septic abortion, chorioamnionitis, and fetal abnormality between the two groups using either IUD or withdrawal.
Data was analyzed by SPSS (Ver. 21) software. Comparison between quantitative variables in the two groups was carried out using Mann-Whitney U-test for data that was not normally distributed and two-sample ttest for data that was. Qualitative variables were analyzed by Chi-squared or Fisher's exact test. $\mathrm{P}$ values $\leq 0.05$ were considered statistically significant.

This study was approved by the ethics committee for researches of the Shahid Beheshti University of medical sciences. The identities of the patients were considered confidential.

\section{RESULTS}

The IUD and withdrawal user groups (112 women each) were assessed for adverse outcomes of pregnancy due to failure of contraception. Mean and SD of age for women were $30.29 \pm 5.26$ years in the IUD users and $31.08 \pm$ 5.63 years in the withdrawal group. The two groups were similar in mean maternal age, obstetrics history such as gravidity, parity, previous abortion, and social variables such as education and jobs; academic education was more prevalent in the withdrawal group, while illiteracy was more common in the IUD group, although the difference in literacy and mean educational levels was not significant between the two groups. Other characteristics of the groups are reported in Table 1.

Table 1: Characteristics of IUD and withdrawal method users.

\begin{tabular}{|llll|}
\hline Characteristics & IUD & Withdrawal & P value \\
\hline Mean age (years) & $30.29 \pm 5.26$ & $31.08 \pm 5.63$ & 0.276 \\
\hline Education & $\begin{array}{l}42.9 \% \\
\text { secondary } \\
\text { school }\end{array}$ & $\begin{array}{l}36.6 \% \\
\text { secondary } \\
\text { school }\end{array}$ & 0.110 \\
\hline Job & $\begin{array}{l}85.7 \% \\
\text { housewife }\end{array}$ & $\begin{array}{l}91.1 \% \\
\text { housewife }\end{array}$ & 0.112 \\
\hline Parity score & $32.1 \%$ two & $36.6 \%$ two & 0.647 \\
\hline $\begin{array}{l}\text { Mean continuation } \\
\text { of method before } \\
\text { conception }\end{array}$ & $\begin{array}{l}30 \pm 24.5 \\
\text { months }\end{array}$ & $\begin{array}{l}40 \pm 48.1 \\
\text { months }\end{array}$ & 0.053 \\
\hline
\end{tabular}

IUD was maintained for $30 \pm 24.5$ months; continuation of IUD was less than one year in 33\%, between 1-2 years in $12.5 \%, 2-3$ years in $25 \%$, and over 3 years in $29.5 \%$. The withdrawal method was used as the method of contraception for $40 \pm 4.81$ months before conception.

Table 2 shows the adverse outcomes. In three cases of the IUD group, ectopic pregnancies were diagnosed at $7 \pm$ 3.6 weeks of conception. One case had unsuccessfully attempted to induce abortion but was later diagnosed with ectopic pregnancy; treatment of ectopic pregnancy was surgical in two cases and medical in one. No case of ectopic pregnancy was reported in case of the withdrawal method; this difference however was not significant. 
Table 2: Adverse pregnancy outcomes in the IUD group compared to the withdrawal group.

\begin{tabular}{|c|c|c|c|c|}
\hline Complications & IUD & Withdrawal & $\begin{array}{l}\text { Relative } \\
\text { risk }\end{array}$ & $\begin{array}{l}P \\
\text { value }\end{array}$ \\
\hline Ectopic pregnancy & 3 out of $112(2.7 \%)$ & 0 out of 112 & - & 0.081 \\
\hline Induced abortion & 8 out of $109(7.3 \%)$ & 6 out of $112(5.3 \%)$ & 1.37 & 0.54 \\
\hline Spontaneous abortion & 19 out of $102(18.6 \%)$ & 9 out of $106(8.5 \%)$ & 2.18 & 0.041 \\
\hline \multirow{2}{*}{$\begin{array}{l}\text { Spontaneous abortion in retained IUD } \\
\text { Spontaneous abortion in removed IUD }\end{array}$} & 3 out of $8(37.5 \%)$ & 9 out of $106(8.5 \%)$ & 4.4 & $0.037 *$ \\
\hline & 16 from $94(17 \%)$ & 9 out of $106(8.5 \%)$ & 2 & 0.087 \\
\hline Bleeding during pregnancy & 35 out of $112(31.3 \%)$ & 19 out of $112(17 \%)$ & 1.8 & 0.01 \\
\hline Bleeding during 1st trimester of pregnancy & 21 out of $112(18.7 \%)$ & 11 out of $112(9.8 \%)$ & 1.9 & 0.01 \\
\hline Bleeding during 2nd and 3rd trimesters of pregnancy & 14 out of $82(17.1 \%)$ & 8 out of $97(8.2 \%)$ & 2 & 0.073 \\
\hline Preterm & 9 out of $82(11 \%)$ & 3 out of $91(3.3 \%)$ & 3.3 & 0.045 \\
\hline Preterm premature rupture of membrane & 8 out of $82(9.7 \%)$ & 1 out of $91(1.1 \%)$ & 8.8 & 0.0098 \\
\hline Foetal abnormality & 0 out of 82 & 1 out of $81(1.2 \%)$ & 0 & 0.347 \\
\hline
\end{tabular}

*Fisher's exact test

Pregnancy with IUD was diagnosed at $5.75 \pm 3.86$ weeks. The IUD was removed at $7.2 \pm 2.76$ weeks in 94 cases of IUD users who were pregnant. Of these 94 cases, 16 had spontaneous abortion. The IUD and its tail were not visible in one case, probably because it had been expelled. In 8 cases, pregnancy had occurred with IUD in situ because the tail of the IUD was not visible after conception; of these 8 cases, 3 had spontaneous abortion. The rate of spontaneous abortion was higher with IUD in situ compared to when IUD was removed, difference however not significant.

In 8 other cases, there was no definite information about the removal of IUD when there was an induced abortion. Overall, 27 cases of the IUD group had abortion at $9 \pm$ 2.7 weeks CI: $95 \%$ (5-14 weeks) and curettage was done in 14 cases of this group. No septic or late abortion was seen in the IUD group. Spontaneous abortion was more prevalent in the IUD group compared to the withdrawal users and this difference was significant $(P=0.015)$. Neither group had a significant rate of induced abortion. Induced abortion was performed in 8 cases of IUD users at $8.52 \pm 2.7$ (4-14 weeks) weeks of pregnancy; by curettage in 5 cases, medical abortion in 2 cases, and both medical and curettage in 1 case.

Vaginal bleeding during pregnancy was higher among the IUD group than the withdrawal group and the difference was significant $(P=0.01)$. Vaginal bleeding occurred during the first trimester in 21 cases, during the second and third trimesters in 14 .

Preterm delivery and preterm premature rupture of membrane was higher in the IUD group than in the withdrawal group and the difference was significant $(\mathrm{P}=$ 0.045 and $\mathrm{P}=0.01$ respectively). Gestational age in this group was 36.6 weeks.
Mean and SD of weight for newborn were $3198 \pm 432$ and $3213 \pm 444$ grams in the IUD and withdrawal groups respectively, difference not significant.

One case of foetal major abnormality was reported in the withdrawal group, but none was observed among the IUD users. There were no reports of chorioamnionitis, low birth weight, or foetal abnormality among IUD users.

\section{DISCUSSION}

\section{Findings and interpretation}

Compared to the withdrawal method, complications in pregnancies increase if this pregnancy is due to failure of $\mathrm{Cu}-\mathrm{T}$ IUD; these adverse effects however are not significant in the removed IUD group.

\section{Strengths and weaknesses of the study}

To mention the strengths and weaknesses, compared to previous studies, we had a control group to detect the adverse pregnancy outcomes. The difference in rate of spontaneous abortion, ectopic pregnancy, fetal abnormality, and vaginal bleeding at the second half of pregnancies was not significant in the comparison between the withdrawal group and the group whose IUD was removed at the early stages of pregnancy. This finding can be explained through early detection of pregnancy and by the removal of IUD during the earlier stages of pregnancy as well.

Retrospectively checking of the records is a weakness of the study; however some data were rechecked with the women but we cannot ignore the recall bias and the reliability of their memory. We missed the evaluation of some cases that had performed abortion primarily and refused to come back to the centers to be visited but having a control group and an insignificant rate of 
induced abortion between both groups makes up for this problem.

\section{Differences in results and conclusions in relation to other studies}

The retained IUD group had more spontaneous and induced abortions compared to the removed IUD one. Spontaneous abortion was significantly less in the withdrawal method users compared to cases with retained IUD, findings in agreement with those of other studies, which suggest that the endometritis and disturbed implantation site may be responsible for the increased abortion rate. ${ }^{5,7,12}$

Moreover, Deveer et al. found that the risk of miscarriage increased significantly when the IUD is retained, compared to when it is removed. ${ }^{8}$ Brahmi et al. demonstrated that if the IUD is left in the uterus, the rate of miscarriage, preterm labour, and chorioamnionitis are increased. ${ }^{5}$ In the present study, the number of cases whose pregnancies with retained IUDs was too low; of these most had higher rates of induced abortions, compared to the removed IUD group. Hence the remaining cases $\left(2^{\text {nd }} \& 3^{\text {rd }}\right.$ trimesters $)$ were mostly those, who had had their IUDs removed; this finding demonstrates that pregnancy if detected earlier the complications of pregnancy are reduced.

There was no significant difference in the rate of induced abortion between the IUD group and withdrawal group in this study; neither was any case of septic or late abortion reported, which may be due to removal of IUD at an earlier stage of pregnancy in most of the cases. In order to minimize the adverse outcomes, it would be better to remove the IUD at an early stage of conception when the tail of the IUD is visible. If the string of IUD is not visible, Schiesser et al. suggest that it would be better to remove the IUD by an ultrasound-guided procedure. ${ }^{9}$ It might be assumed that removing IUD in the circumference of no visible string tail is advised but manipulation of the uterine cavity has its own complications. Further studies are needed to evaluate and confirm the advantages of removing IUD in this condition.

More cases of vaginal bleeding were seen in the IUD group than the withdrawal group, due to abortion in the first trimester, and preterm delivery during the second half of pregnancy.

Preterm delivery and preterm premature rupture of membrane was higher in the IUD group than in the withdrawal group. Preterm premature rupture of membrane was probably due to subclinical infection of membranes. No evidence of chorioamnionitis was observed in our study, which could be due to the fact that the IUD had been removed in almost all of the cases, contrary to the Ganer et al. study, who reported that the incidence of chorioamnionitis was significantly higher in both the retained and removed IUD groups, compared to the no IUD group. ${ }^{10}$ Wegmann et al. proposed that in pregnancy, there are pro-inflammatory cytokines and the shifting from lymphocyte $\mathrm{T}$ helper cell 1 to a $\mathrm{T}$ helper cell 2 that functionally maintain pregnancy and do not permit the fetus to be rejected; ${ }^{7}$ since IUD causes inflammation in the endometrial surfaces and disturbs implantation, due to increase in inflammatory markers in IUD group, ${ }^{8}$ it could be proposed that inflammation and preterm premature rupture of membranes are expected in these conditions.

Occurrence of pregnancy, including ectopic pregnancy, is less prevalent among IUD users compared to those using the withdrawal method. However, if pregnancy occurs, the probability of ectopic pregnancy is increased. The type of IUD affects the rate of ectopic pregnancy as well. The rate of ectopic pregnancy with the levonorgestrel IUD was reported to be higher than with the Cu380A in some studies. ${ }^{11}$ In our study, 3 cases of ectopic pregnancy occurred, all of whom had used Cu-IUD.

Some studies report higher rates of fetal abnormalities in pregnancies with IUD, ${ }^{5}$ but in the present study, no fetal abnormality was recorded, indicating no reason for teratogenicity in pregnancy with IUD either. In the Kim et al. study, no significant congenital malformation was observed between IUD users compared to the 'no IUD' groups. $^{12}$

\section{Relevance of the findings: implications for clinicians and policymakers}

IUD is one of the common contraception methods since it has almost no systemic effect on the user and has high efficacy. However, similar to any modern contraception, it has its own complications, such as failure of the method and unplanned outcomes, e.g. pregnancy. Unplanned pregnancy can be reduced by improving the insertion technique by checking the position of IUD by ultrasound. ${ }^{13}$ Earlier removal of the IUD in pregnant women can also reduce the rate of adverse effects.

On the other hand, as mentioned, withdrawal has the highest prevalence as a method of contraception in Iran. In fact, many clients in Iran, who have higher education and a better economic status, unfortunately use the withdrawal method, being afraid of side effects of modern contraceptive methods. ${ }^{2}$ Counseling and awareness of safety and efficacy of modern contraceptives is necessary to encourage couples to use effective contraception. Failure of the withdrawal method is currently responsible for approximately half of the induced abortions $;{ }^{2}$ as mentioned in his editorial by Amy, unintended pregnancy with this method has a high rate and consequently unsafe abortion has a negative impact on the physical and mental health of these women, their families and health system services. ${ }^{14}$ If free access to safe and effective contraceptive methods be restricted due to decline in total fertility rate in Iran, methods like withdrawal will become far more prevalent, and we 
should be prepared to face related public health consequences.

Finally, health care providers should bear in mind the greater need for comprehensive counseling and creating awareness among these groups, improving the technique of IUD insertion, and following up of cases to detect any complications.

\section{Unanswered questions and future research}

Whether removing IUD at the earlier stage of pregnancy has lesser complications, compared to no IUD group needs a larger study to confirm. To prevent induced or spontaneous abortions due to failure of contraceptives, this study recommends determining the precise failure rate of withdrawal to clarify the proportional differences between the complications of the two methods.

\section{CONCLUSION}

In this study despite IUDs being used by thousands of healthy Iranian women and the adverse effects that dissatisfaction with this method has on its continuation and family planning programs, these effects can be minimized by early removal of the IUD.

\section{ACKNOWLEDGEMENTS}

This study was supported and funded by the infertility and reproductive health research centre of the Shahid Beheshti medical science University of Tehran, Iran. The authors wish to thank Dr. S. J. Hosseini, Dr. R. Taheripanah, and also Dr. A.R. Farsar, vice-chancellor for Health, for their contributions. The authors would also like to thank the clinic staff for their cooperation. The authors would like to acknowledge Ms. Niloofar Shiva for editing of English grammar and syntax of the manuscript.

Funding: This study was funded by the infertility and reproductive health research centre of the Shahid Beheshti Medical Science University of Tehran, Iran Conflict of interest: None declared

Ethical approval: The study was approved by the ethics committee for researches of the Shahid Beheshti University of Medical Sciences. This Study is a graduation thesis as well.

\section{REFERENCES}

1. National Institute for Health Research (NIHR). Health observatory: first report of the Islamic republic of Iran's multiple-indicator demographic and health survey 2010, 2012. Available at: http://nihr.tums.ac.ir/Index.aspx. Accessed December 2012.

2. Erfani A, Yuksel-Kaptanoglu I. The use of withdrawal among birth limiters in Iran and Turkey: demographic and health research. Stud Family Planning. 2012;43:21-32.

3. Trussell J. Contraceptive failure in the United States. Contraception. 2011;83:397-404.

4. Mansour D, Inki P, Gemzell-Danielsson K. Efficacy of contraceptive methods: a review of the literature. Eur J Contracept Reprod Health Care. 2010;15:4-16.

5. Brahmi D, Steenland MW, Renner RM, Gaffield ME, Curtis KM. Pregnancy outcomes with an IUD in situ: a systematic review. Contraception. 2011;85(2):131-9.

6. Persian Medical Group. Annual report: section of reproductive health care affiliated with vicechancellor for health affairs in Shahid Beheshti University of medical sciences, 2012-2013. Available at: persianmedicalgroup.blogspot.com.

7. Wegmann TG, Lin H, Guilbert L, Mosmann TR. Bidirectional cytokine interactions in the maternalfoetal relationship: is successful pregnancy a $\mathrm{TH} 2$ phenomenon? Immunol Today. 1993;14(7):353-6.

8. Deveer R, Engin-Ustun Y, Sarikaya E, Aydogan P, Doğanay M, Mollamahmutoğlu L. Comparison of Creactive protein levels in pregnancies with retained and removed intrauterine device. J Matern Foetal Neonatal Med. 2011;24(9):1152-4

9. Schiesser M, Lapaire O, Tercanli S, Holzgreve W. Lost intrauterine devices during pregnancy: maternal and foetal outcome after ultrasound-guided extraction. Ultrasound Obstet Gynaecol. 2004;23(5):486-9.

10. Ganer H, Levy A, Ohel I, Sheiner E. Pregnancy outcome in women with an intrauterine contraceptive device. Am J Obstet Gynaecol. 2009;201(4):381.e1.

11. Backman T, Rauramo I, Huhtala S, Koskenvuo M. Pregnancy during the use of levonorgestrel intrauterine system. Am J Obstet Gynaecol. 2004;190(1):50-4.

12. Kim SK, Romero R, Kusanovic JP, Erez O, Vaisbuch E, Mazaki-Tovi S, et al. The prognosis of pregnancy conceived despite the presence of an intrauterine device (IUD). J Perinat Med. 2010;38(1):45-53.

13. Ozgu-Erdinc AS, Tasdemir UG, Uyguret D, Aktulay A, Tasdemir N, Gulerman HC. Outcome of intrauterine pregnancies with intrauterine device in place and effects of device location on prognosis. Contraception. 2014;89(5):426-30

14. Jean-Jacques Amy. Editorial: the shortest lecture on fertility control. Eur J Contracept Reprod Health Care. 2009;14:321-3.

DOI: $10.5455 / 2320-1770 . i j r \operatorname{cog} 20140986$

Cite this article as: Majdfar Z, Meshkat M, Tavana A, Tavana Sh, Amiri Z, Ehdaeevand F, Saharkhiz N, Fallahian M. Comparing the adverse outcomes of contraception failure between IUD and withdrawal methods. Int J Reprod Contracept Obstet Gynecol 2014;3:631-5. 